\title{
DO GRAFO DO DESEJO AOS QUATRO DISCURSOS DE LACAN
}

\author{
Marta Regina de Leão D'Agord ${ }^{*}$ \\ Universidade Federal do Rio Grande do Sul, \\ Instituto de Psicologia, \\ Porto Alegre, RS, Brasil.
}

\begin{abstract}
Resumo: Este trabalho analisa uma etapa do percurso do Lacan pesquisador,envolvendo questões metodológicas na passagem do grafo do desejo à formalização do matema dos quatro discursos. No grafo, a linha em formato de anzol cortando as duas linhas horizontais configurava o efeito de discurso em três etapas, as quais se mostraram equivalentes às três estruturas clínicas. Com os quatro discursos, Lacan estabelece uma estrutura de quatro posições sobre as quais giram quatro elementos. $O$ matema dos quatro discursos nos remete às operações da estrutura do grupo de Klein. Entretanto, duas regras restringem a permutabilidade: o movimento de um quarto de giro dos elementos apenas em um sentido; em segundo lugar, nas quatro posições prévias, há uma disjunção entre as posições de saber e verdade. Podemos então concluir que os quatro discursos consistem em uma apropriação parcial da estrutura do grupo de Klein, de modo a demarcar a diferença entre a psicanálise e o discurso científico.
\end{abstract}

Palavras-chave: Psicanálise. Lógica. Grafo do desejo. Quatro discursos.

* $\quad$ Endereço para correspondência: mdagord@terra.com.br 
"Le réel dont je parle est absolument inapprochable, sauf par une voie mathématique" (Lacan, 1971-1972/2011, p.68).

\section{Introdução}

Este trabalho faz parte do projeto de análise do uso que Lacan fez do método lógico-matemático para a fundamentação do conceito de sujeito do inconsciente. Este artigo é resultado da pesquisa que compara a elaboração do grafo do desejo com a formulação dos quatro discursos. Com o grafo, era conquistada uma figuração do modo como a escuta psicanalítica operava. Com os quatro discursos, trata-se de formalizar esse método. Agora não se discute apenas a apropriação do método estrutural, mas o uso do que é o fundamento desse método: a formalização.

O foco deste trabalho envolve a trajetória da pesquisa conduzida por Lacan entre o final da década 1950 e o início da década 1970. Essa localização requer uma leitura histórica e crítica do Seminário e dos Escritos. Nosso corpus de análise é constituído pelos livros do Seminário e textos dos Escritos e dos Outros Escritos, que abrangem um período muito produtivo no ensino de Lacan, que vai do final dos anos 1950 ao início dos anos 1970. Vale lembrar que o ensino de Lacan corresponde ao seu Seminário e, a obra de Lacan, aos seus Escritos e Outros Escritos. Esses, apesar de escritos, não são textos acadêmicos. Predominam trabalhos escritos para serem lidos em congressos e jornadas de instituições psicanalíticas. Em seu Seminário, Lacan anunciava que falava como analisante. Apesar de definir previamente uma temática específica para cada ano de Seminário, e um roteiro de leituras correspondente, muitas ideias lhe ocorriam subitamente enquanto falava, e até seus tropeços de língua se tornavam conteúdo do Seminário.

O objetivo deste trabalho é analisar a elaboração que conduziu Lacan à formalização do matema dos quatro discursos. Este trabalho enfoca, portanto, a articulação entre aspectos metodológicos e conceituais na concepção das formações do inconsciente como produções discursivas e a formalização do discurso por meio das estruturas algébricas. Nossa ideia norteadora é que o matema dos quatro discursos representa uma inovação no uso das

estruturas, antes, topológicas, agora, topológicas e algébricas. Essa inovação produzirá efeitos conceituais no ensino lacaniano na década 1970. 


\section{Da Linguística à Lógica}

Inicialmente, Lacan (1901-1981) buscara recursos metodológicos na Linguística. Desse diálogo, surgiu o grafo do desejo. Pois, se até 1955, no Seminário O eu na teoria de Freud e na técnica da psicanálise, Lacan trabaIhava com o conceito de ordem simbólica, após seu contato com as pesquisas linguísticas passará a empregar o conceito de cadeia significante.

A busca dos instrumentos lógicos acompanhava Lacan desde a estrutura quaternária dos esquemas $L, Z$ e $R$, inspirada pelo quadrado das oposições de Aristóteles. Não seria coincidência que as limitações que esse quadrado aristotélico apresentava, a saber, limitar-se a um sistema de classes de proposições diferenciadas em universais e particulares, afirmativas e negativas (considerando que a matemática dos grupos surgirá bem posteriormente), poderiam ter gerado efeitos nas limitações dos esquemas. Pois, enquanto desenvolvia os esquemas $L$ e $Z$, Lacan não havia ainda operado com a concepção de falta no Outro. Será no grafo do desejo que aparecerá a distinção entre o Outro como tesouro dos significantes e o significante da falta no Outro.

Para analisar a passagem do grafo aos quatro discursos, localizamos um marco de referência no Seminário De um outro ao outro, quando Lacan observa, sobre o grafo, que a linha retroativa em anzol, figurando um ponto de interrogação, pode ser comparada ao "fundamento da investigação científica" (Lacan, 1968-1969/2008, p. 261). Assim, apesar dos aspectos estruturais sustentados na diferença entre enunciado e enunciação, entre fala e linguagem, o grafo guarda aspectos de figura, representação, analogia: a figura do ponto de interrogação e as flechas de retroação. Lacan estava declarando, portanto, que já concluíra uma etapa inicial de seu projeto, no qual propunha a busca de equivalências com "a linguagem da antropologia ou com os mais recentes problemas da filosofia" (Lacan, 1960/1998, p. 241). Dez anos antes, iniciara a apropriação do método estrutural pelos instrumentos da Linguística, mas agora era preciso criar um instrumento próprio, ou seja, fazer a formalização dos conceitos psicanalíticos.

Com o matema dos quatro discursos, Lacan avançará na formalização da psicanálise, isto é, para a conquista de "um discurso sem fala" (un discours sans parole), para o qual foi necessária a elaboração dos matemas como estruturas algébricas.

Entretanto, o matema dos quatro discursos, como uma máquina de um quarto de volta, não atingirá uma formalização equivalente à da estrutura do grupo de Klein, pois restará uma diferença que caracteriza a especificidade da ciência do inconsciente: o corte ou a descontinuidade entre saber e verdade. Como veremos a seguir, na estrutura de lugares do matema dos quatro discursos, não há vetor entre o lugar da produção resultante do saber e o lugar da verdade. 


\section{O grupo de Klein}

Será no Seminário A lógica do fantasma (1966-1967) que Lacan explicitará o uso das operações do grupo de Klein. Para isso, ele anunciará o artigo "Acerca del sentido del término estructura en matemáticas", de Marc Barbut (1966), como uma de suas referências.

Em matemática, um grupo é um conjunto de elementos associados a uma operação de associatividade, que combina dois elementos para formar um terceiro. Além da associatividade, é preciso que se defina o elemento neutro e o simétrico (por oposição ou inversão). As operações binárias nos grupos são vinculadas, portanto, à associatividade, à operação do elemento neutro (identidade) e a do elemento simétrico. Um grupo de Klein é aquele que opera com 4 elementos. Trata-se, portanto, de uma estrutura diferente das estruturas topológicas, como os toros, que são aquelas que "formalizam as noções intuitivas de vizinhança, proximidade, interior, exterior e fronteira, tomadas de nossa percepção do espaço" (Barbut, 1966, p. 16, tradução nossa). O conjunto de transformações de um grupo de Klein leva a uma operação involutiva, isto é, a combinação de duas operações sobre um elemento produz o retorno ao ponto inicial. Por exemplo: dado x, a negação ou simétrico de x é não-x; e a negação de não-x é x.

A operação involutiva aponta para a repetição (insistência, retorno), da qual se conhece o resultado (a identidade), mas não o processo de dupla negação operante (e subjacente). Assim, a análise que Lacan introduzira no Seminário $A$ identificação, referente à função significante como pura diferença, encontrará, na operação involutiva do grupo de Klein, um novo fundamento. O significante é sempre diferente de si mesmo, pois ele é efeito de uma operação entre dois elementos, que gera um terceiro pela inversão do primeiro, por exemplo: $x$ é invertido, gerando $-x$, e a inversão do inverso, gera novamente o elemento inicial $x$. Mas esse $x$ que surgiu no terceiro tempo não é o mesmo $x$ que o primeiro $x$, pois ele é efeito de um circuito ou operação involutiva. Assim, com o grupo de Klein, é possível explicar que o significante, sem significar-se a si mesmo e sem recorrer a um elemento externo, pode gerar a identificação.

Barbut (1966) explica por figuras o funcionamento da operação involutiva. Assim, na figura a seguir será exemplificada a operação involutiva por meio das operações binárias: (1) ausência de mudança (operador elemento neutro); (2) mudança de atributo 1, mudança de atributo 2 ou mudança de atributos 1 e 2 (operador de elemento simétrico). Podemos: não mudar os atributos e voltar ao estado inicial; mudar o atributo cor (de escuro para claro ou de claro para escuro, tal como aparece na operação denominada $b$ na figura a seguir); podemos mudar o atributo forma (de quadrado para círculo ou de círculo para quadrado tal como aparece na 


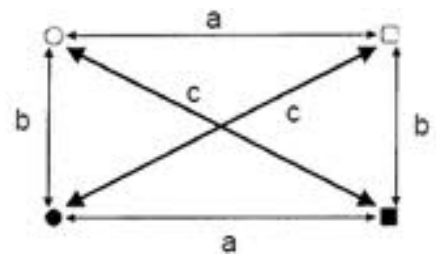

Figura 1. O grupo de Klein (Recuperada de http://ebookbrowse.com/ barbut-pdf-d116120630 (Acesso livre)

operação denominada $a$ na figura a seguir); mudar os atributos cor e forma (tal como aparece nas diagonais c, figura 1)

Todas as três operações são involutivas, pois a cada duas operações é possível retornar ao estado inicial. E o conjunto dessas transformações é um grupo de Klein. A estrutura do grupo de Klein é uma estrutura lógica que permitirá a Lacan propor, inclusive, uma releitura da que ele utilizara até então, a estrutura da metáfora, para explicar a estrutura do inconsciente. No Seminário A lógica do fantasma, vai utilizar o grupo de Klein para mostrar a origem lógica da substituição metafórica na origem. $\mathrm{O}$ efeito de significação, o quarto elemento da fórmula da metáfora, poderá ser o sintoma, no sentido de retorno de um significante primeiro que ficou perdido (recalcado); ou seja, um elemento que foi negado reaparecerá.

$\mathrm{E}$, seguindo coerentemente com a proposição de que o inconsciente está estruturado como uma linguagem, Lacan poderá, então, reler o grafo à luz da concepção lógica de que o que falta exerce uma função na estrutura.

No grafo, o matema S( $\mathbb{A}$ ) era lido como não há Outro do Outro, e agora será lido como o equivalente da presença do que é chamado o um-a-mais ou o que falta. Mas foi preciso registrar um circuito ou uma série para que a falta pudesse ser identificada.

\section{O grafo do desejo: entre a analogia e a estrutura}

\section{O grafo e as estruturas clínicas}

Podemos, então, buscar uma equivalência entre as transformações e as três etapas do Grafo: Grafo II, Grafo III (Che Vuoi?) e Grafo completo (figuras a seguir). Cada uma dessas etapas, não genéticas, representaria três momentos da estrutura constitutiva do sujeito, como efeito de três diferentes percursos do discurso enunciativo no grafo: o sujeito identificado ao I(A) da demanda, o sujeito do fantasma e o sujeito que seria o efeito do discurso pelo circuito completo. 
A questão que nos mantém aquém de uma estrutura de grupo de Klein é que essas três etapas guardam entre si uma relação de condição, uma é a condição necessária para a outra, apesar da temporalidade do só-depois. De modo que somente atingindo o grafo completo se poderia saber das etapas anteriores. Assim, não seria possível a reversibilidade de grafo completo para grafo II.

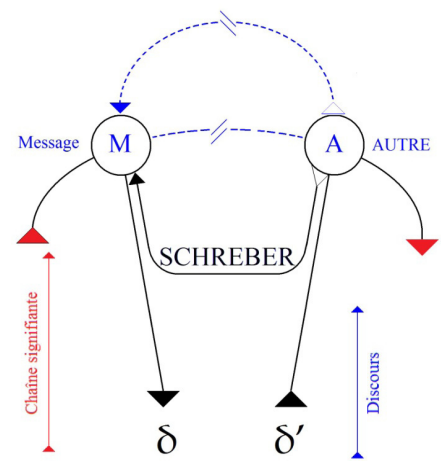

Figura 2. grafo II. Lacan, J. Le Séminaire, Les formations de l'inconscient, 1957-1958. Lição de 08.01.1958 Acesso em 10 de dezembro de 2011. Recuperada de http:// staferla.free.fr/.(Acesso livre).

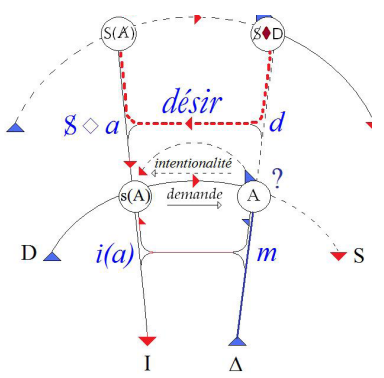

Figura 3. Grafo III. Lacan, J. Le Séminaire, Le Désir et son interpretation, 1958-1959, Lição de 22.4.1959. Acesso em 10 de dezembro de 2011. Recuperada de http:// staferla.free.fr/.(Acesso livre). 


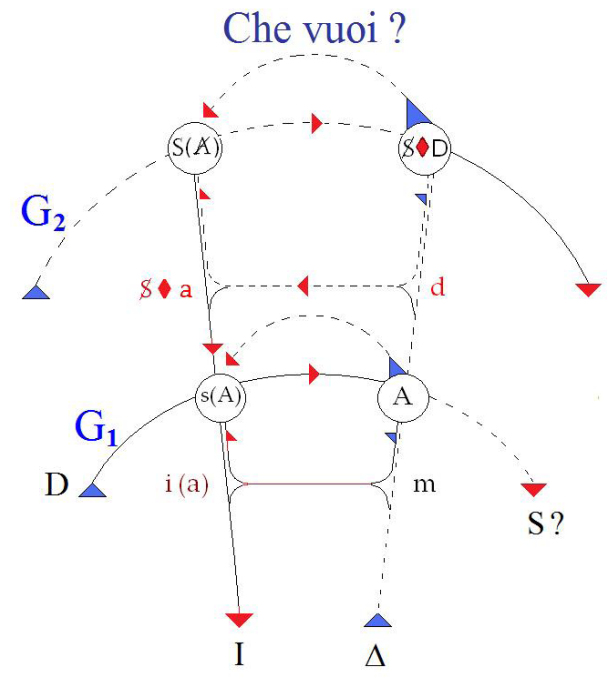

Figura 4. Grafo completo. Lacan, J. Le Seminaire, Le Désir et son interpretation, 1958-1959, Lição de 29.4.1959. Acesso em 10 de dezembro de 2011. Recuperada de http://staferla.free.fr/. (Acesso livre)

Será possível uma leitura topológica do grafo como estrutura do oito interior, isto é, uma estrutura projetiva de inversão com transformação sem a perda da continuidade e do fechamento.

\section{A analogia com o oito interior}

Antes de chegar à formulação de que o sujeito é plano tal como apresenta no Seminário A identificação (1961-1962), Lacan pensou, com o chamado esquema $Z$, o sujeito distribuído e, portanto, dividido em quatro pontos. Era já um sujeito planar, pois a distribuição ocorria no espaço bidimensional representado pela forma de uma letra $Z$.

No grafo do desejo encontramos dois vetores orientados em sentidos distintos: a linha pontilhada que representa o inconsciente faz o sentido inverso à linha cheia. Se a estrutura do grafo comporta dois sentidos é porque se trata de uma divisão subjetiva entre pré-consciente e inconsciente. Essa divisão, mesmo que esteja planificada nas setas do grafo, ainda comporta uma terceira dimensão, enquanto projeção de uma virada 
no segundo andar do grafo, aquela que transforma o $\mathrm{s}(\mathrm{A})$ do primeiro andar em S( $\mathbb{A}$ ) no segundo andar. Para Marchilli, Carbajal, D'Angelo (1984) e Eidelsztein (1992) essa virada corresponde a um oito interior enquanto espacialidade projetiva. Um oito interior é projetivo, pois é uma estrutura planar que é percebida como tridimensional.

Mas essa relação seria de analogia ou de homologia? Se ainda dependente de configurações espaciais comuns, isto é, da percepção de uma terceira dimensão, então seria uma analogia. Estamos, portanto, ainda no campo da analogia quando comparamos o grafo com as dimensões espaciais.

O grafo demonstra como um significante representa um sujeito para outro significante. No Seminário O eu na teoria de Freud e na técnica da psicanálise (1954-1955), Lacan havia esboçado o circuito da cadeia do discurso na forma circular de encontro do sujeito com a cadeia de significantes. Esse encontro entre discurso e cadeia era comparado ao jogo repetitivo do "fort-da". Nesse jogo, o que surpreendeu Freud (1920) é que a enunciação e o gesto distanciavam-se, o que mostra que o circuito passa a ter vida própria, independente do objeto, a vida do circuito é o gozo e este não é mais corporal, mas psíquico. O gozo é a reencenação de um momento de criação, em que o sujeito distanciou-se do objeto. Ora, esse distanciamento foi o encontro com o circuito, com o encadeamento de significantes. Desse momento em diante, o reencontro com o objeto será determinado pelo circuito: o circuito determina, portanto, o modo de gozo enquanto reencontro com a cena na qual o sujeito se separou do objeto, e que é justamente a cena na qual surgiu o sujeito. O sujeito surge desse corte, em que, pela linguagem, ele se separa do objeto. Mas, nesse momento, separa-se também daquele que fora antes da separação. É essa dupla separação que faz que Eidelzstein destaque as duas revoluções:

Com uma revolução $S_{1}$ e $S_{2}$ em relação circular podemos contar "um", mas para que se conte "sujeito" tem que haver ao menos duas revoluções, ou seja, $\mathrm{S}_{1}-\mathrm{S}_{2} \mathrm{e}$ $\mathrm{S}_{1}-\mathrm{S}_{2}$, outra cena, a volta sobre si mesmo no toro e a volta em torno à superfície do toro, ou a torsão que faz o oito interior, como uma torsão sobre si mesmo. (Eidelsztein, 2006, p. 149)

O corte, a subversão, a virada em oito interior no grafo e a volta sobre si mesmo no toro antecipariam a ideia de giro de $1 / 4$ de volta que, depois, vamos encontrar no matema dos quatro discursos.

\section{Os limites do grafo e sua superação}


Para avaliar o grafo enquanto estrutura quaternária, Eidelsztein (2005) recorre a Dienes, A geometria através das transformações, em que este último define grupo como um conjunto cujos elementos devem estar ligados mediante uma operação. O grupo de Klein é um grupo de quatro elementos ligados por três movimentos definidos, cada um desses movimentos é tal que, aplicados duas vezes, retorna à posição inicial. E também quando aplicamos dois dos movimentos o resultado é equivalente ao terceiro movimento. Quaisquer três movimentos que cumpram com o anterior, unidos ao movimento "nada", revelam a estrutura do grupo de Klein (Eidelsztein, 2005, p. 155).

Eidelsztein (2005) observa que, ao delimitar aos menos duas das quatro funções que inscrevemos no grafo do desejo, podemos também avançar na conceitualização das demais. Os quatro elementos seriam $A$, $s(A), S(A)$ e $S<>D$. As funções que correspondem à cadeia inferior seriam transformadas, tal como apresentado no quadro a seguir (tabela 1):

Tabela 1

As transformações no grafo

\begin{tabular}{llll}
\hline $\begin{array}{l}\text { Transformação espaço e } \\
\text { tempo }\end{array}$ & $\begin{array}{l}\text { do fechamento } \\
\text { à pontuação (espaço) } \\
\text { [vertical] }\end{array}$ & $\begin{array}{l}\text { da sincronia em diacronia } \\
\text { (tempo)[vertical] }\end{array}$ \\
\hline $\begin{array}{l}\text { Transformação } \\
\text { Função do corte }\end{array}$ & pela & $\begin{array}{l}\text { Função de Corte da de } \\
\text { Pontuação [em 8 interior] }\end{array}$ & $\begin{array}{l}\text { Função de Corte da de de dem } 8 \text { interior] } \\
\text { demanda [em }\end{array}$ \\
\hline
\end{tabular}

Nessa tentativa de aproximar o grafo ao grupo de Klein, o autor argentino encontrou uma anomalia que nos ajuda a pensar o que teria conduzido Lacan a abandonar a analogia do Nome-do-Pai e iniciar uma tentativa de homologia matemática. Eidelsztein (2005) observa que o significante do Nome-do-Pai, apesar de ser o da lei no Outro, é um significante como os outros. Mas ainda há um significante diferente de todos os outros: será o $\mathbf{S}(\mathbb{A})$. Porém como situar esse significante distinto de todos os outros? Lacan então compara o significante $S(\mathbb{A})$ a uma volta a mais ou a menos que, depois de um percurso completo em uma bobinagem de um toro, nunca poderá ser contada.

Assim, a transformação de $\mathrm{A}$ em $\mathrm{S}(\mathrm{A})$, ao invés de ser concebida espacialmente, por projeção ou deformação de superfície, poderia ser logicamente fundamentada? Era isso que Lacan já anunciava em "Subversão do sujeito e dialética do desejo no inconsciente freudiano", texto apresentado em um Congresso de Filosofia em 1960. 
O que o grafo nos propõe agora, situa-se no ponto em que toda cadeia significante se honra ao fechar sua significação. Se é preciso esperar tal efeito da enunciação inconsciente, é aqui em $\mathrm{S}(\mathrm{A})$, e há que lê-lo: significante de uma falta no Outro, inerente à sua função mesma de ser o tesouro do significante.... A falta de que se trata é ... que não há Outro do Outro.... Partiremos do que a sigla S ( $A$ ) articula por ser antes de tudo um significante.... Esse significante, portanto, será aquele para o qual todos os outros significantes representam o sujeito: ou seja, na falta desse significante, todos os demais não representariam nada. Já que nada é representado senão para algo. Ora, estando a bateria dos significantes, tal como é, por isso mesmo completa, esse significante só pode ser um traço que se traça por seu círculo, sem poder ser incluído nele. Simbolizável pela inerência de um (-1) no conjunto dos significantes. (Lacan, 1998, pp. 832-833)

Trata-se aqui de fazer uso da álgebra enquanto um discurso sem fala, ao mostrar que, dado que esse significante da falta no Outro, quando simbolizado como (-1), poderá ser submetido ao cálculo algébrico. E, nessa linguagem,"seu enunciado iguala-se à significação" (p. 833):

S (significante)

s (significado)

Lacan chegou ao número imaginário $(\sqrt{ }-1)$ com o qual trabalhará a volta não contada ou contada a mais na superfície de um toro no Seminário A identificação (1961-1962). Trata-se de pensar o Outro como função em homologia à função lógico-matemática. Pois $(\sqrt{ }-1)$ não é nenhum número, "é apenas um algoritmo, mas um algoritmo que serve" (Lacan, 1961-1962/2003, p. 111).

A partir de um significante simbolizável como (-1), chega-se ao significado, com o número imaginário. Eis a homologia ao que não tem existência. Lacan tomou então um número que tem a propriedade de não ser nenhum número e o utilizou para representar o que falta ao sujeito, na medida em $S(\mathbb{A})$, como o impronunciável e impensável, é o que impede o sujeito de localizar-se no Ser como "penso". O impensável é o que impede o sujeito de se esgotar como "penso" e esse $S(\mathbb{A})$ representa a volta mais além da demanda (Eidelsztein, 2005, p. 194). Assim, a analogia bíblica de um nome não pronunciável foi substituída por uma função que propiciou o estabelecimento de uma homologia.

\section{Da topologia de superfícies à álgebra}


Ao mesmo tempo em que trabalhava sua concepção de sujeito plano, aquele para quem duas dimensões bastam, Lacan já operava com a álgebra e com os grupos. A topologia das superfícies foi importante para formular uma relação entre dois toros enlaçados e a estrutura da neurose tal como encontramos no Seminário $A$ identificação. De modo que o encontro faltoso da demanda de um com o desejo do outro mostrava topologicamente o objeto $a$, como um vazio central. Com a topologia de superfícies, conseguia mostrar a extração do objeto $a$. Esse conceito de extração já havia sido apresentado com o esquema R em "De uma questão preliminar a todo tratamento da psicose".

Mas o que ainda estava em questão era a ideia de uma analogia: a neurose como uma analogia aos dois toros enlaçados, na formulação de que o desejo do sujeito nunca se encontra com o desejo do Outro. Essa incomensurabilidade terá uma nova formulação por meio da concepção de incompletude do universo do discurso. Será então possível passar da analogia com os toros enlaçados para a homologia da falha no universo do discurso e assim mostrar que a falha é estrutural.

O Seminário A identificação mostra os passos dessa trajetória, quando Lacan explora a diferença entre as classes e os conjuntos ao analisar o paradoxo de Russell. Mais do que as bordas das superfícies, estava em questão a exclusão interna ao conjunto: o conjunto vazio. Eis a trajetória para a concepção de traço unário, a base poder operar algebricamente com o que, antes, ele chamava de sua concepção de significante. Um significante representa um sujeito para outro significante. Se antes essa formulação nos remetia a um encadeamento discursivo, ao efeito de discurso, agora essa formulação vai equivaler a uma função matemática. $O$ falo, o traço unário e o sujeito do inconsciente dão a partida para a série, mas estão excluídos dela.

Em "Subversão do sujeito e dialética do desejo no inconsciente freudiano", Lacan (1960/1998) ainda apoiava sua argumentação em analogias espaciais e em uma concepção de Real oriunda da Física a fim de pensar o inconsciente. Mas, apesar do uso de metáforas espaciais, nesse mesmo texto Lacan já começava a operar com a teoria dos conjuntos e com a falha no universo do discurso: "Esse gozo cuja falta torna o Outro inconsistente, será ele, então, o meu?" (p. 834).

Lacan antecipava, em 1960, uma concepção lógico-matemática do Real, para a qual o Seminário De um Outro ao outro constitui um marco decisivo nesse percurso, com um estudo das implicações do teorema da incompletude de Gödel e com a enunciação de um projeto de elaboração de um discurso sem fala (un discours sans parole). Este viria a tomar forma com os matemas, isto é, a algebrização.

Se no Seminário O desejo e sua interpretação (1957-1958) antecipava o uso do teorema da incompletude com a formulação de que não há Outro do Outro, mostrando a necessidade distinguir entre Outro e A, será 
somente durante o Seminário De um Outro ao outro (1968-1969) que será dado o salto para a fundamentação lógico-matemática dessa distinção. Até o Seminário 6, e com o uso do grafo, a função de Outro poderia ser confundida com a pessoa do Outro. Mas A é estrutural, e o Outro é histórico. Se o A não rege o Outro, o dito primeiro se confundiria com a voz onipotente de um Outro encarnado em A.

\section{Das três etapas do grafo à estrutura dos quatro discursos}

No grafo do desejo, acompanhava-se o percurso do sujeito nos desfiladeiros da cadeia significante, percurso demarcado por quatro pontos de encontro entre o enunciado e a enunciação. No andar inferior, a significação do que era dito, a significação imaginarizada. No andar superior, a abertura de sentido, a outra cena, sustentada como a verdade: não há Outro do Outro, nenhum significante é todo, nenhuma significação é absoluta. Em relação à demanda incondicional, restava a condição do desejo como absoluta: a insatisfação estrutural.

O grafo do desejo mostrava um percurso da direita para a esquerda, de trás para frente. Nesse percurso, o ponto de chegada poderia ser:

1) no Grafo II: em I(A). E que pode ser representado pelo seguinte enunciado: O que queres de mim é isso.

2) no Grafo III: na pergunta. E que pode ser representado pelo enunciado: $O$ que queres que eu faça?

3) no Grafo completo: no fantasma. E que pode ser representado por: O Outro tem algo que me falta.

O matema dos quatro discursos é assim apresentado no Seminário 17, O avesso da psicanálise (1969-1970): há um circuito (os lugares) no qual se produzem quatro subestruturas do discurso. Segue-se, da regra de composição de estruturas, o requisito da exigência de uma invariância. Ou seja, os elementos podem ocupar qualquer dos quatro lugares, desde que seja mantida a ordem entre os elementos. A seriação ou ordenação dos elementos é um limite, é um "não" que define a estrutura do matema dos quatro discursos. Essa manutenção da ordem dos elementos afasta-se da regra da associatividade com permutabilidade do grupo de Klein.

Em "Radiofonia" é explicitado esse limite do matema: 1.fica limitado por um não, por não ser possível a um vetor chegar à verdade; 2 . fica limitado ao número de quatro por uma revolução não permutativa de sua posição em quatro termos.

E os operadores seriam a progressão e a regressão em relação à verdade: a verdade da castração. Aqui a lei aparece não na exigência do giro 
em um quarto de volta dos elementos nos quatro lugares, mas na impossibilidade e impotência em se furtar à castração. Em homologia com o grupo de Klein, mantém-se, entretanto, a inversão na diagonal, o avesso: do Discurso do Mestre ao Discurso do Analista e vice-e-versa.

\section{O uso da expressão avesso e a origem do matema}

Precisamos aqui retornar ao Seminário A lógica do fantasma, em que, na lição de 14.12.1966, Lacan revela o estatuto estrutural da relação entre o inconsciente e o cogito cartesiano. Ao discurso do mestre, identificado ao cogito, é que o discurso psicanalítico será o avesso. O cogito é o melhor avesso (le meilleur envers) do estatuto do inconsciente e o cogito foi condição para pensar o inconsciente. Pois ali onde penso, não me reconheço, não sou. E onde não sou, o inconsciente é. Se Lacan destaca que isso teria ficado por tanto tempo obscuro no nível do discurso do mestre, era justamente por estar em um lugar que por sua própria estrutura mascarava a divisão do sujeito. E o discurso do analista, ao explicitar a divisão do sujeito, será considerado como aquele cuja emergência permitiu que os outros fossem lidos.

Assim, se o matema dos quatro discursos (figura 5) tem como matriz o discurso do mestre, é porque nesse discurso está escrita a relação fundamental $\left(S_{1} \rightarrow S_{2}\right)$ da qual o sujeito (\$) e mais-de-gozar (a) são efeitos. Mesmo que a divisão do sujeito pela linguagem esteja velada. (Tabela 2)

Os quatro discursos são a articulação significante na qual a fala irá se alojar. Trata-se, portanto, de um aparelho, o discurso sem a fala (parole), cuja mera presença domina e governa tudo o que eventualmente pode surgir de fala (Cf. Lição 10.6.1970). É nesse sentido que Lacan dedicará o Seminário 18, do ano seguinte (1971), à formulação de que não haveria discurso que não fosse do semblante. Tratava-se de mostrar que o agente ou semblante não se confunde com o falante, mas que é de um lugar na estrutura discursiva que se trata.
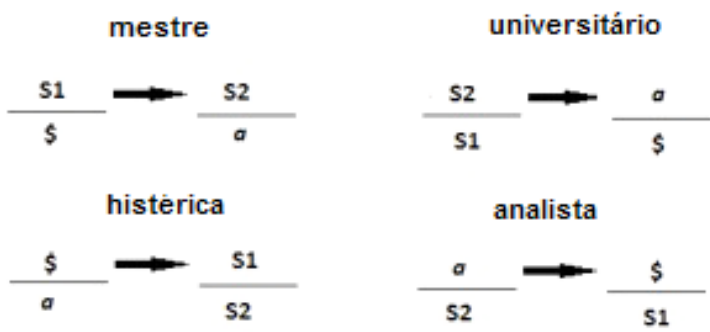

Figura 5. O matema dos quatro discursos. 
Tabela 2

A matriz dos quatro discursos

\begin{tabular}{|c|c|c|}
\hline Os 4 elementos & \multicolumn{2}{|c|}{ Os 4 lugares } \\
\hline & agente & trabalho \\
\hline$\delta \quad a$ & verdade & produção \\
\hline
\end{tabular}

Lacan utiliza, portanto, os esquemas quadrípodes (como denominava os quatro discursos), como um meio para indicar a relação de função, no sentido matemático do termo. Com a função matemática será possível escrever duas ordens de relações que corresponderiam ao que se pode registrar, via simbólico, do Real. Esse é o sentido da expressão "escrever o Real" (Lacan, 1969-1970/1992, p. 179, Lição de 17.6.1970).

A função do $S_{1}$, o significante-mestre, é o que define a legibilidade em qualquer discurso; e se a estrutura dos discursos coincide com a constituição do sujeito, é porque o significante-mestre ocupa o lugar de agente, de semblante. Pois o $S_{1}$ é oco, é o significante do qual não há significado, e que, quanto ao sentido, simboliza seu fracasso (Lacan, 19721973/1985c, p. 107, lição de 13.3.1973).

\section{A disjunção entre saber e verdade}

A disjunção entre saber e verdade explica por que os tetrápodes têm quatro pés, mas apenas três lados. Há um vazio central em torno ao qual a demanda circula, mas não há resposta. $O$ desejo relança o mais-de-gozar. No discurso do mestre, o significante mestre $\left(\mathrm{S}_{1}\right)$, ao ser emitido em direção aos meios do gozo, que são aquilo que se chama o saber $\left(\mathrm{S}_{2}\right)$ determina a castração. No discurso histérico deixa-se a palavra ao Outro, precisamente como lugar do saber recalcado $\left(\mathrm{S}_{2}\right.$ sob a barra): a alternativa: ou não penso, ou não sou, se produz no lugar dominante. A função desse discurso é deixar claro que o sujeito é posto diante desse vel, dessa disjunção que se exprime pelo não penso ou não sou. Ali onde penso, não me reconheço, não sou, é o inconsciente. Ali onde sou, é mais do que evidente que me perco.

No discurso do analista, o que se pode saber $\left(\mathrm{S}_{2}\right)$ é o que está no lugar da verdade. Essa relação será lida como "um saber que faz função de verdade", revelando que "estamos condenados a não poder denunciar o que quer que seja a não ser mediante um semi-dizer" (Lacan, 19691970/1992, p. 102, Lição de 11.3.1970). 
Eis a especificidade da disjunção entre saber e verdade. O matema dos quatro discursos revela que não há como o saber recobrir a verdade. Portanto, a verdade tem a estrutura de ficção. Isso não é algo que nos condena, mas justamente nos liberta do absoluto.

Enfim, no discurso universitário, em que se alicerça o discurso da ciência, o saber tem lugar dominante e o significante-mestre se encontra no nível de sua verdade. Ou seja, é suposta uma verdade ao saber, enquanto que o sujeito desaparece sob o imperativo de "continuar a saber".

O discurso do psicanalista pode ser analisado à luz do que podemos nomear, a partir de uma releitura de Freud (Freud, 1920), de um sujeito do "fort-da". O que faz o sujeito produzir é a causa do desejo, como no "fort-da", mas essa produção nunca cessa, o saber está no lugar da verdade, a verdade do sujeito é o saber. $\mathrm{O}$ discurso do mestre, que toma de Hegel o modelo do senhor e servo, é o avesso do discurso do psicanalista, pois há a tentativa de dominar o saber, de fazer o saber produzir. Enquanto, no discurso do psicanalista, o agente é o gozo e por isso o gozo aparece como causa motora do circuito, como o que faz o sujeito produzir, mas produzir o que já estava lá, os $\mathrm{S}_{1}$ determinantes. Já no discurso do mestre, a causa motora é o domínio, o $S_{1}$, o domínio do saber produz o gozo, mas esse gozo não retorna ao sujeito: o sujeito está alienado do gozo.

O que diferencia a Psicanálise da Linguística e da Antropologia é que ela considera tanto a causa, o que antecede o sujeito (determinações simbólicas) como o sujeito em relação com a causa (na forma de gozo). Se a linguagem antecede o sujeito, o dizer depende de um ato. O dizer é ato. Nesse sentido, a psicanálise se ocupa com a relação do sujeito com seu dizer, ora, seu dizer, no que se refere à verdade, ao que o causa, é semi-dizer. Não há como antecipar, chegar a uma causa primeira, pois esta já está dada antes do sujeito, eis a alienação. Por isso, a verdade é semi-dita, semi-dizer.

Os quatro discursos mostram, portanto, quatro modos que correspondem a quatro posições gramaticais, em relação ao dito, ou seja, quatro modos de fazer com o dito. Vamos comparar com o que Lacan (19711972/2012) apresenta na lição de 9.2.1972 do Seminário 19, ...Ou pior:"Je te demande de me refuser ce que je t'offre, parce que c'est pas ça" (Peço-te que me recuses o que te ofereço, porque não é isso) (Lacan, 2012, p. 90). Obteremos quatro posições gramaticais que equivalem à estrutura dos quatro discursos (Tabela 3):

Tabela 3

A equivalência entre a estrutura dos quatro discursos e as quatro posições gramaticais.

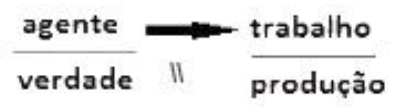

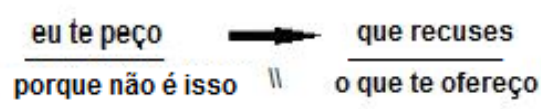

Psicologia USP, São Paulo, 2013 24(3), 431-451. 
$\mathrm{Na}$ análise gramatical do enunciado anterior, Lacan retoma o tetrápode como uma estrutura de 4 pés e 3 lados, pois não há vetor que transite do lugar da produção ao lugar da verdade. Em toda demanda e em toda oferta, nunca se encontra a satisfação, há um "não é isso". Logo, a insatisfação é a satisfação da estrutura, como destaca Eidelsztein (2005): "Toda satisfação se faz insatisfatória e toda insatisfação se faz satisfatória por estrutura" (p. 172).

Dessa forma, é possível considerar que o tetrápode é formado por quatro tríades, de forma que cada uma delas está ordenada em relação com a falta ou hiância representada pelo objeto $a$. Falta no Outro e falta no sujeito. Furo, vazio que é impossível preencher. Se, somente com o advento do discurso do psicanalista foi possível desvelar os outros discursos, é porque a psicanálise revelou essa falha estrutural.

O que era a torsão de um oito interior no grafo, será quiasma (movimento de inversão) na estrutura dos quatro discursos. O grafo mostrava como ocorria a relação entre a fala e seu sentido como efeito retroativo do discurso. Nos quatro discursos, está em jogo a escrita, e não o sentido. Trata-se de ler.

Se, do discurso psicanalítico, há sempre alguma emergência a cada passagem de um discurso a outro, é porque no discurso psicanalítico o saber faz função de verdade, ele não é a verdade, mas semi-dizer. Portanto, sempre restará algo esquecido. E o que resta esquecido na travessia de cada discurso ao outro, senão o impossível e a impotência? Atravessa-se para outro discurso ao se fazer semblante de que é possível se furtar à castração, esquecendo impotência e impossibilidade.

O matema dos quatro discursos é, portanto, o efeito da apropriação do método lógico-matemático que torna possível pensar a operação de um elemento sobre outro, produzindo um terceiro. Assim, o que era o matema da constituição do sujeito vai se tornar a matriz da operação lógica dos discursos. Logo, $\mathrm{S}_{2}$ no lugar da verdade vai significar a operação discurso do psicanalista, isto é, a verdade funcionando como uma ficção. E o seu inverso, $S_{2}$ no lugar do outro (trabalho), vai significar a operação discurso do mestre, isto é, uma produção que é perda. Se o grafo do desejo envolvia um percurso de fala, o segundo vai envolver as relações lógicas. Se no grafo, a diacronia cortada pela sincronia produzia a retroatividade, nos quatro discursos os elementos giram sobre uma estrutura de lugares, eis a operação que produz um terceiro elemento. Há uma operação a cada quarto de giro, e não um percurso retroativo como no grafo.

É possível, ainda, analisar a diferença entre o grafo e os quatro discursos a partir da distinção entre escrita e exercício da fala: "o sujeito é dividido pela linguagem [pois] um dos seus registros pode satisfazer-se com a referência à escrita, e o outro, com o exercício da fala" (Lacan, 1971/2009, p. 117). Em nossa leitura, propomos a seguinte formulação: o sujeito é dividido pela linguagem porque o significante pode tanto ser 
mencionado como usado. O significante tem como referência (menção) o Real da letra, mas depende também do exercício (uso) simbólico da fala. Assim, podemos considerar que Lacan explora, com o grafo, o significante tal como é usado na fala e os efeitos simbólicos de formas distintas de uso, chegando à formulação de três estruturas clínicas, três formas distintas de relação do sujeito ao significante. Assim, o grafo mostrava a constituição do sujeito nessa divisão entre o real da letra e a fala, isto é, na relação entre um lugar do Outro (letra) e um desejo do Outro (fala).

A elaboração dos quatro discursos é o estabelecimento de um discurso sem fala (pois escrito), buscando, na lógica, a formalização e a auto-evidência. Estava em jogo o estatuto de ciência para a psicanálise. Mas essa ciência tem como emblema a verdade como estrutura de ficção, é uma ciência do saber fazer com o semblante, com o que a fala e as palavras proporcionam. Assim, tratava-se de utilizar os recursos lógicos de escrita e formalização na medida em que esses permitiam mostrar o que é próprio do sujeito do inconsciente: a falta a ser, a verdade como ficção, o saber como saber-fazer.

\title{
From graph of desire to Lacan's four discourses
}

\begin{abstract}
This paper analyzes a stage of Lacan's work as a researcher, concerning methodological issues in the move from the graph of desire to formalization of the mathema of four discourses. In the graph, the line-shaped hook cutting the two horizontal lines configured the effect of discourse in three stages, which proved to be equivalent to three clinical structures. With the four discourses, Lacan establishes a framework of four basic positions on which occurs a turn of four elements. The mathema of four discourses reminds us of the operations of the group structure of Klein. However, two rules restrict the interchangeability: the movement of one quarter of rotation of the elements only in a sense; secondly, in the four basic positions, there is disjunction between the positions of know (savoir) and truth. We can then conclude that the four discourses consist of a partial appropriation of the structure of the Klein group in order to demarcate the difference between psychoanalysis and scientific discourse.
\end{abstract}

Keywords: Psychoanalysis. Logic. Graph of desire. Four discourses.

\section{Del grafo del deseo a los cuatro discursos de Lacan}

Resumen: Este trabajo analiza una etapa de la obra de Lacan como investigador, en relación con las cuestiones metodológicas en el paso del grafo del deseo a la formalización de los matemas de los cuatro discursos. En el grafo, la línea en forma de 
gancho corta las dos líneas horizontales configurando el efecto del discurso en tres etapas, que han demostrado ser equivalentes a tres estructuras clínicas. Con los cuatro discursos, Lacan establece una matriz de cuatro posiciones y sobre esta se produce un giro de cuarto de vuelta de cuatro términos. El matema de los cuatro discursos nos recuerda las operaciones de la estructura del grupo de Klein. Sin embargo, dos reglas restringen la permutación: el movimiento de la rotación de los términos sólo en un sentido, en segundo lugar, en las cuatro posiciones básicas, hay una separación entre las posiciones de saber y verdad. Podemos entonces concluir que los cuatro discursos consisten en una la apropiación parcial de la estructura del grupo de Klein con el fin de delimitar la diferencia entre el psicoanálisis y el discurso científico.

Palabras-clave: Psicoanálisis. Lógica. Grafo del deseo. Cuatro discursos.

\section{Du graphe du desir aux quatre discours de Lacan}

Résumé: Cet article analyse une étape de l'œuvre de Lacan en tant que chercheur, concernant les questions méthodologiques dans le mouvement du graphe du désir à la formalisation du matheme de quatre discours. Dans le graphe, la ligne en hameçon en coupant les deux lignes horizontales détermine l'effet de discours en trois étapes, qui se sont révélées équivalentes à trois structures cliniques. Avec les quatre discours, Lacan établit un cadre de quatre postes dans la mesure où les quatre éléments tournent. Le matheme de quatre discours nous rappelle les opérations de la structure du groupe de Klein. Cependant, deux règles limitent l'interchangeabilité des elements: le mouvement d'un quart de rotation des éléments seulement dans un sens, d'autre part, dans les quatre positions de la structure, il ya une disjonction entre les positions de savoir et de la vérité. Nous pouvons donc conclure que les quatre discours se composent d'une apropriation partielle de la structure du groupe de Klein afin de délimiter la différence entre la psychanalyse et le discours scientifique.

Mots-clés: Psychoanalyse. Logique. Graphe du désir. Quatre discours.

\section{Referências}

Barbut, M. (1966). Acerca del sentido del término estructura en matemática. Les Temps Modernes (246), 81-101. (Traducción y notas de Juan Bauzá a partir de Cahiers 
de lectures freudiennes, 10). Recuperado de: http://ebookbrowse.com/barbutpdf-d116120630

Carbajal, E., D’Angelo, R., \& Marchilli, A. (1984). Una introducción a Lacan. Buenos Aires, Argentina: Editorial Lugar.

Eidelsztein, A. (1992). Modelos, esquemas y grafos en la enseñanza de Lacan. Buenos Aires, Argentina: Manantial.

Eidelsztein, A. (2005). El grafo del deseo. Buenos Aires, Argentina: Letra Viva.

Eidelsztein, A. (2006). La topología en la clínica psicoanalítica. Buenos Aires, Argentina: Letra Viva.

Freud, S. (1920). Jenseits des Lustprinzips. In Gesammelte Werke (Vol. 13, pp. 3-69). Frankfurt: Fischer.

Lacan, J. (1985a). O Seminário. Livro 2: o eu na teoria de Freud e na técnica da psicanálise. Rio de Janeiro, RJ: Jorge Zahar. (Trabalho original publicado em 1954-1955)

Lacan, J. (1985b). O Seminário. Livro 11: os quatro conceitos fundamentais da psicanálise. Rio de Janeiro, RJ: Jorge Zahar. (Trabalho original publicado em 1964)

Lacan, J. (1985c). O Seminário. Livro 20: mais, ainda. Rio de Janeiro, RJ: Jorge Zahar. (Trabalho original publicado em 1972-1973)

Lacan, J. (1991). L'envers de La psychanalyse. Paris: Seuil. (Trabalho original publicado em 1969-1970)

Lacan, J. (1992). O Seminário. Livro 1: o avesso da psicanálise (1969-1970). Rio de Janeiro, RJ: Jorge Zahar. (Trabalho original publicado em 1969-1970)

Lacan, J. (1998). Subversão do sujeito e dialética do desejo no inconsciente freudiano. In Escritos (pp. 807-842). Rio de Janeiro, RJ: Jorge Zahar. (Trabalho original publicado em 1960)

Lacan, J. (2002). O Seminário. Livro 6: o desejo e sua interpretação. Publicação de circulação interna da Associação Psicanalítica de Porto Alegre. (Trabalho original publicado em 1958-1959)

Lacan, J. (2003). Radiofonia. In Outros escritos (pp. 400-447). Rio de Janeiro, RJ: Jorge Zahar.

Lacan, J. (2006a). Le Séminaire. Livre 16 : d'un autre à l'autre. Paris: Seuil. (Trabalho 
original publicado em 1968-1969)

Lacan, J. (2006b). Le Séminaire. Livre 18 : d'un discours qui ne serait pas du semblant. Paris: Seuil. (Trabalho original publicado em 1971)

Lacan, J. (2007). O Seminário. Livro 23: o sinthoma. Rio de Janeiro, RJ: Jorge Zahar. (Trabalho original publicado em 1977-1976)

Lacan, J. (2008). O Seminário. Livro 16: de um outro ao outro. Rio de Janeiro, RJ: Jorge Zahar. (Trabalho original publicado em 1968-1969)

Lacan, J. (2009). O Seminário. Livro 18: de um discurso que não fosse semblante. Rio de Janeiro, RJ: Jorge Zahar. (Trabalho original publicado em 1971)

Lacan, J. (2011). Je parle aux murs. Paris: Seuil. (Trabalho original publicado em 19711972)

Lacan, J. (2012). O Seminário. Livro 19: "...ou pior". Rio de Janeiro, RJ: Jorge Zahar. (Trabalho original publicado em 1971-1972)

Lacan, J. (1958-1959/1996). Le Séminaire: Le désir et son interpretation (1958-1959). Association Freudienne internationale. Publication hors commerce.

Lacan, J. (n.d.). Le Séminaire: les formations de l'inconscient (1957-1958). Recuperado de http://staferla.free.fr/

Lacan, J. (n.d.). Le Séminaire: le désir et son interpretation (1958-1959). Recuperado de http://staferla.free.fr/

Lacan, J. (n.d.). Le Séminaire: Ia logique du fantasme (1966-1967). Recuperado de http:// staferla.free.fr/

Lacan, J. (n.d.). Le Séminaire: ...Ou pire (1971-1972). Recuperado de http://staferla.free. $\mathrm{fr} /$

Lacan, J. (n.d.). Le Séminaire: les non dupes errent (1973-1974). Recuperado de http:// staferla.free.fr/

Lacan, J. (1961-62/1996). L'Identification, Séminaire 1961-1962. Publication hors commerce. Document interne à L'Association Freudienne Internationale.

Lacan, J. (1961-1962/2003). O Seminário. Livro 9: a identificação (1961-1962). Recife: CEF. (Publicação não comercial). 
Lacan, J. (2003b). O Seminário. Livro 14: la lógica del fantasma., Buenos Aires: EFBA. (Trabalho original publicado em 1966-1967. Publicação não comercial)

Lacan, J. (2003c). O Seminário. Livro 15: O ato analítico. Buenos Aires, Argentina: EFBA. (Trabalho original publicado em 1967-1968. Publicação não comercial)

Recebido: $13 / 02 / 13$

Aceito: 23/09/2013 